\title{
An Efficient Model to Calculate Axial Natural Vibration Frequency of Power Transformer Winding
}

\author{
Kaiqi $\mathrm{Li}^{1}$, Jian Guo ${ }^{1 *}$, Jun $\mathrm{Liu}^{2}$, Anhong Zhang ${ }^{2}$, and Shaojia $\mathrm{Yu}^{2}$ \\ ${ }^{1}$ Nanjing University of Aeronautics and Astronautics, Nanjing 211106, China \\ ${ }^{2}$ Hangzhou Qiantang River Electric Group Co. Ltd., Hangzhou 311243, China
}

(Received 29 March 2016, Received in final form 1 August 2016, Accepted 1 August 2016)

\begin{abstract}
In the design of transformer winding, natural vibration frequency is an important parameter. This paper presents a 2D model to calculate axial vibration natural frequency of power transformer winding based on the elastic dynamics theory, and according to the elastic support equivalent principle of radial pressboards. The 3D model to calculate natural vibration frequency can be simplified as a $2 \mathrm{D}$ one as the support of pressboards on the winding is same. It is verified that results of the $2 \mathrm{D}$ model are consistent with those of $3 \mathrm{D}$ one, but the former can achieve much higher calculation efficiency. It shows that increasing the width and number of pressboards can improve axial natural frequency through formula analysis and simulation, and also the relations between the changes of axial pre-compression and axial natural vibration frequency on the windings are investigated. Finally, the proposed 2D model's effectiveness is proved when compared with tested ones.
\end{abstract}

Keywords : power transformer, winding, efficient finite element model, axial natural vibration frequency

\section{Introduction}

Natural vibration frequency of winding is a significant parameter during the design of a power transformer [1], and resonance will appear when it is close to the frequency of electrodynamic force [2]. The vibration may bring dynamic force much bigger than pre-compression, therefore the pressboards in oil channel will be separated from winding discs, and result in the winding loosing, reversing, or even collapsing, which ultimately cause the instability of transformer winding [3, 4]. For a large power transformer, radial natural vibration frequency is ignored as it is far bigger than the frequency of electrodynamic force. However, axial natural vibration frequency is greatly reduced due to the adoption of wire-pressboard-wire form for the winding's axial structure, so that it is easily to occur resonance, which has become a part of reason for the axial instability and operating noise. Therefore, it is important to calculate the natural vibration frequency of transformer winding, and avoid the frequency of axial dynamic short circuit force by improving the structure form.

(C)The Korean Magnetics Society. All rights reserved.

*Corresponding author: Tel: +84892368

Fax: +84892368, e-mail: kaiqilizhu@qq.com
At present, there are two methods to calculate the axial natural vibration frequency: centralized parameter method based on the mass spring damper system and finite element method. In literature [5], axial vibration of the whole coil of cable transformer is modeled by centralized parameter method, whose parameter is determined by the equal fundamental of first-order natural frequency and same model shape, and modal analysis of the coil is conducted. However, this method cannot ensure the parameters' accuracy, which can't obtain the accurate calculation results. Finite element method can be applied to the complex model and boundary condition, and the application process is more flexible, since it can well balance the winding structure and mechanical properties of the support, which can achieve an accurate result than that of the traditional centralized parameter method. In literature [6], a 3D finite element model to calculate natural vibration frequency of power transformer is established. Literature [7] investigates the relations between axial pre-compression and axial natural vibration frequency, and measures to improve axial stability of transformer are presented. The 3D finite element model can reach a good result in transformer axial natural frequency calculation, but the complexity of modeling process and high computational cost limit its application in practical engineering.

Based on the elastic dynamics theory [8], and according 
to the elastic support equivalent principle of radial pressboards, a 2D model to calculate axial vibration natural frequency of power transformer winding is presented. It is verified that results of the $2 \mathrm{D}$ model are consistent with those of 3D model, but the former can achieve much higher calculation efficiency. Finally, the proposed 2D model's effectiveness is validated when compared with tested ones.

\section{2D Finite Element Model}

\subsection{Establishment of the model}

3D axisymmetric model of the large power transformer winding is shown in Fig. 1. Winding discs are composed of line segments separated by insulating pressboards, and they are clamped between the clamping pieces. The pressboard plays a supporting role in the two adjacent winding discs, which is an important influence factor on the reliability of mechanical system, so it should be well considered in the calculation model of natural vibration frequency. It should be a 3D calculation model because the pressboards are arranged along the circumferential direction of the winding, but this will cost a lot for the calculation of natural vibration frequency.

When the pressboard is compressed by the winding's axial electromagnetic force, the stress it subjected to is:

$$
\delta=\frac{F}{\sum A}
$$

where, $d$ is the stress the pressboard, and $F$ is the axial pressure of the pressboard, $\Sigma A$ is the sum contact area between the pressboard and the winding discs.

According to Hooke theorem, relations between stress and strain of the pressboard is

$$
\delta=E \cdot \varepsilon
$$

where, $\varepsilon$ is the pressboard's strain and $E$ is the elastic modulus of pressboard.

Compression on the pressboard will lead the winding's

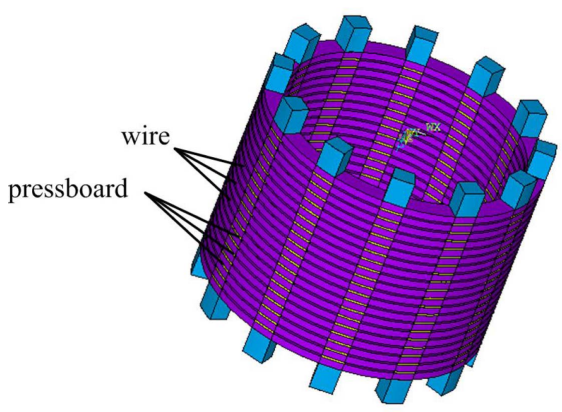

Fig. 1. (Color online) 3D axisymmetric model of winding. displacement of $\Delta Z$ in the axial direction. The displacement and force satisfies:

$$
F=k \cdot \Delta Z
$$

where, $k$ is the equivalent elastic modulus which reflects the support of the pressboard to the winding discs.

As the relation between winding's displacement and pressboard's strain is $\Delta Z \propto \varepsilon$, so

$$
F \propto k \cdot \varepsilon
$$

Relationship between the equivalent elastic modulus, the elastic modulus of the pressboard and the contact area between the pressboard and the winding discs is obtained by combining formula (1), formula (2) and the formula (4):

$$
\frac{F}{\varepsilon}=E \cdot \sum A \propto k
$$

It can be seen that support of the pressboard to the winding discs is invariant as long as $E \cdot \Sigma A$ is a constant, so the $3 \mathrm{D}$ model can be simplified as a $2 \mathrm{D}$ model to calculate natural vibration frequency.

Figure 2(a) is an axisymmetric 3D model. The pressboard and the winding discs are full contacted, so it can be simplified as a 2D model, which is shown in Fig. 2 (b). To ensure the support of the pressboard to the winding discs keep invariant, and according to the formula (5), the equivalent elastic modulus of the pressboard should satisfy:

$$
E_{\mathrm{e}}=\frac{E \cdot \sum A}{\pi\left(r_{2}^{2}-r_{1}^{2}\right)}
$$

where, $E_{\mathrm{e}}$ is the equivalent elastic modulus, $r_{1}, r_{2}$ are the inner and outer radius of the winding discs, respectively.

Influence of the mass of pressboard on the axial natural vibration frequency should also be considered, the density of pressboard can be written as

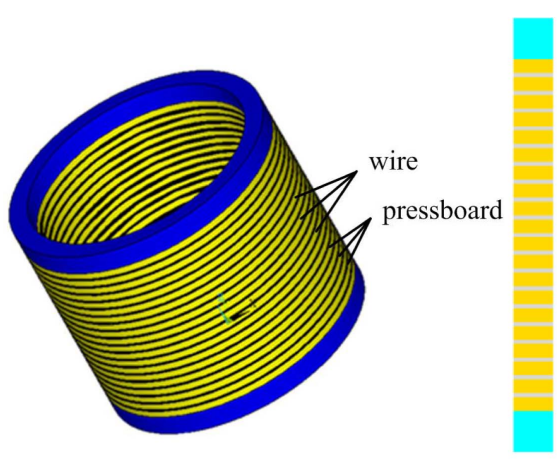
(a) 3D model
(b) $2 \mathrm{D}$ model

Fig. 2. (Color online) Axisymmetric models of winding. 


$$
\rho_{\mathrm{e}}=\frac{\rho \cdot \sum A}{\pi\left(r_{2}^{2}-r_{1}^{2}\right)}
$$

where, $\rho_{\mathrm{e}}$ is the equivalent density and $\rho$ is the actual density.

\subsection{Governing equation}

Assuming that winding discs are composed of line segments separated by insulating pressboards, and they are clamped between the clamping pieces. To gain a better understanding of its' dynamic process, the winding is regarded as a mechanical system which is composed of the entities which are elastic contacted $[9,10]$.

Based on the finite element model seen in Fig. 2(b), and according to the elastic dynamics theory, the equation of motion is expressed as

$$
\boldsymbol{M} \ddot{\boldsymbol{Z}}+\boldsymbol{C} \dot{\boldsymbol{Z}}+\boldsymbol{K} \boldsymbol{Z}=\boldsymbol{F}(t)+\boldsymbol{M g}
$$

where, $\boldsymbol{Z}$ is displacement of the mass from its equilibrium, $\boldsymbol{M}$ is mass of the system, $\boldsymbol{C}$ is co-efficient of viscous damping, $\boldsymbol{K}$ is a stiffness of the system, $\boldsymbol{F}(t)$ is input force applied to the pressboard and $g$ is acceleration of gravity.

Assuming that damping and the input force are zero:

$$
\boldsymbol{M} \ddot{\boldsymbol{Z}}+\boldsymbol{K} \boldsymbol{Z}=0
$$

Solving the linear homogeneous ordinary differential equation would result as:

$$
\boldsymbol{Z}=\hat{\boldsymbol{Z}} \sin (\omega t+\theta)
$$

where, $\hat{\boldsymbol{Z}}$ is the main vibration model.

Substitute equation (10) to equation (9):

$$
\left(\boldsymbol{K}-\omega^{2} \boldsymbol{M}\right) \hat{\boldsymbol{Z}}=0
$$

To have a nonzero solution, the equation should satisfy:

$$
\left|\boldsymbol{K}-\omega^{2} \boldsymbol{M}\right|=0
$$

By solving equation (12), the angular frequency $\omega_{i}$ can be achieved. Axial natural vibration frequency is required as below:

$$
f_{i}=\omega_{i} /(2 \pi)
$$

\section{Results}

\subsection{Results of the 2D model}

The model proposed by Literature [11] is taken as an example to verify the 2D model's effectiveness. Parameters are shown in Table 1.

\begin{tabular}{|c|c|c|c|c|c|}
\hline & $1^{\text {st }}$ axial & $2^{\text {nd }}$ axial & $3^{\text {rd }}$ axial & $4^{\text {th }}$ axial & $5^{\text {th }}$ axial \\
\hline $\begin{array}{c}\text { Axial natural } \\
\text { vibration } \\
\text { frequencies/Hz }\end{array}$ & 362.8 & 884.2 & 1510.5 & 2167.4 & 2826.8 \\
\hline Mode shapes & $\underline{E}$ & $\begin{array}{l}= \\
= \\
= \\
=\end{array}$ & $\begin{array}{l}0 \\
0 \\
0 \\
\end{array}$ & 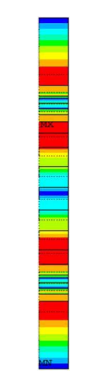 & 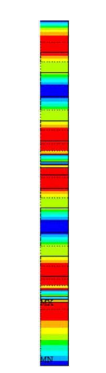 \\
\hline
\end{tabular}

Computed results and the axial natural vibration frequency mode shapes of the winding are shown in Table 2.
Table 1. Parameters of model.

\begin{tabular}{lc}
\hline \hline Number of the winding discs & 20 \\
Height of the winding discs $/ \mathrm{m}$ & 0.01345 \\
Inner radius of the winding discs $/ \mathrm{m}$ & $0.437 / 2$ \\
External radius of the winding discs $/ \mathrm{m}$ & $0.507 / 2$ \\
Passion ratio of the coil & 0.35 \\
Density of the coil $/\left(\mathrm{Kg} / \mathrm{m}^{3}\right)$ & 8930 \\
Young modulus of the coil/ $\mathrm{Pa}$ & $12 \mathrm{e} 10$ \\
Size of the oil duct $/ \mathrm{m}$ & $0.0754 / 19$ \\
Size of the end insulation $/ \mathrm{m}$ & 0.05 \\
Number of the pressboards & 12 \\
Contact surface area of the pressboards to winding & 0.016 \\
discs $/ \mathrm{m}^{2}$ & \\
Passion ratio of the pressboards & 0.35 \\
Density of the pressboards $/\left(\mathrm{Kg} / \mathrm{m}^{3}\right)$ & 2884 \\
Young modulus of the pressboards $/ \mathrm{Pa}$ & $8 \mathrm{e} 8$ \\
Equivalent density of the pressboards $/\left(\mathrm{Kg} / \mathrm{m}^{3}\right.$ ) & 901 \\
Equivalent young modulus of the $\mathrm{pressboards} / \mathrm{Pa}$ & $2.5 \mathrm{e} 8$ \\
\hline
\end{tabular}

Table 2. (Color online) Vibration models according to natural vibration frequency.

\subsection{Comparison of natural frequency}

Computed results of 3D model are compared with those of 2D model. Fig. 3(a) shows the 3D meshed model and Fig. 3(b) is the 1st axial natural vibration frequency mode

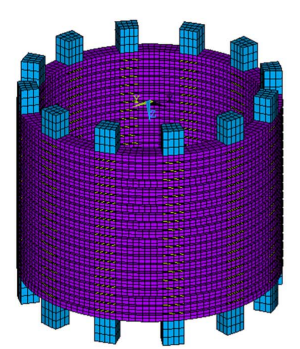

(a) 3D meshed model

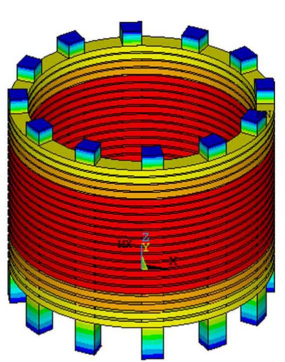

(b) $1^{\text {st }}$ axial mode shape
Fig. 3. (Color online) Vibration models according to natural vibration frequency. 
Table 3. Comparison of $2 \mathrm{D}$ model's calculated values and $3 \mathrm{D}$ model's ones.

\begin{tabular}{cccccc}
\hline \hline \multirow{2}{*}{ Mode } & \multicolumn{2}{c}{ 2D model's calculated values } & & \multicolumn{2}{c}{ 3D model's calculated values } \\
\cline { 2 - 3 } & $\begin{array}{c}\text { Axial natural vibration } \\
\text { frequencies } / \mathrm{Hz}\end{array}$ & Computing time/s & & $\begin{array}{c}\text { Axial natural vibration } \\
\text { frequencies } / \mathrm{Hz}\end{array}$ & Computing time/s \\
\hline $1^{\text {st }}$ axial & 362.8 & 7.18 & 362.09 & 283.47 \\
$2^{\text {nd }}$ axial & 884.2 & & 878.49 & \\
\hline
\end{tabular}

Table 4. Comparison of $2 \mathrm{D}$ model's calculated values and tested ones.

\begin{tabular}{ccc}
\hline \hline Mode & $\begin{array}{c}\text { 2D model's calculated } \\
\text { results/Hz }\end{array}$ & $\begin{array}{c}\text { Experimental } \\
\text { results } / \mathrm{Hz}\end{array}$ \\
\hline $1^{\text {st }}$ axial & 362.8 & 380 \\
$2^{\text {nd }}$ axial & 884.2 & 840 \\
\hline
\end{tabular}

shape of 3D model.

Table 3 lists the comparison of the calculated results and computing time of the two models. It can be seen that calculated results of the two methods are nearly same, but the $2 \mathrm{D}$ model costs less time.

\subsection{Experimental verification}

Table 4 shows the comparison of computed results with experimental results. Because of the small difference between the model's material properties and the actual material properties, there are some errors between the 2D model results and experimental results. However, it can be seen that the two results are basically consistent, which can meet the requirements of engineering design and prove the validity of the proposed method.

\section{Influencing Factors}

From the equation (12), it is known that natural vibration frequency is related to the equivalent stiffness and mass of the mechanical system. Mass of the system is generally determined by the electromagnetic design and economic cost of the transformer, which can't adjust much. The system's stiffness depends on the support of the pressboard to the winding discs. On one hand, it can be realized by changing pressboard's number and size to adjust the axial natural frequency, on the other hand, by changing the pre-compression is also a way to adjust it, which can be an effective way to avoid the resonance of winding [12].

Influencing factors of the axial natural frequency are studied based on the parameters of Table 1. Table 5 shows the natural vibration frequency according to the widths of pressboard, and Fig. 4 is the corresponding curve of press-
Table 5. Natural vibration frequency according to the widths of pressboard.

\begin{tabular}{cccc}
\hline $\begin{array}{l}\text { Width } \\
\text { of pressboards/mm }\end{array}$ & $\begin{array}{c}1^{\text {st }} \text { axial } \\
/ \mathrm{Hz}\end{array}$ & $\begin{array}{c}2^{\text {nd }} \text { axial } \\
/ \mathrm{Hz}\end{array}$ & $\begin{array}{c}3^{\text {rd }} \text { axial } \\
/ \mathrm{Hz}\end{array}$ \\
\hline 10 & 187.2 & 458.5 & 784.6 \\
20 & 263.5 & 644.2 & 1101.7 \\
30 & 321.1 & 783.8 & 1339.6 \\
40 & 368.9 & 899.2 & 1535.8 \\
50 & 410.6 & 998.9 & 1704.9 \\
60 & 447.6 & 1087.2 & 1854.4 \\
\hline
\end{tabular}

board's width and frequency. It can be seen that increasing the width of pressboards can improve axial natural frequency as the support of the pressboard to the winding discs grows, which makes the system's equivalent stiffness $\mathrm{K}$ getting larger.

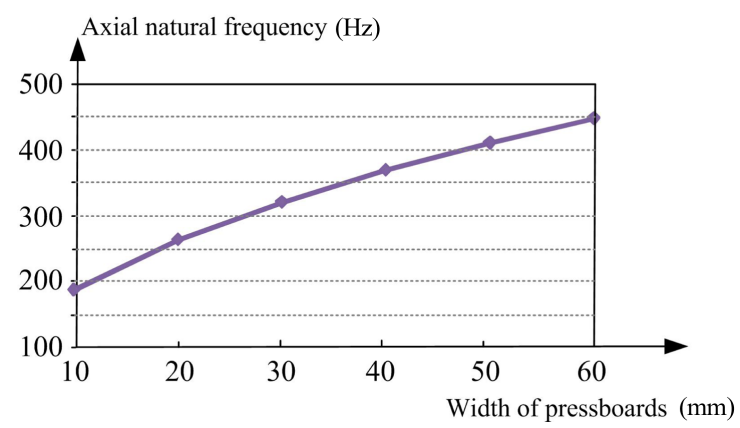

Fig. 4. (Color online) Curve of pressboard's width and frequency.

Table 6. Natural vibration frequency according to the number of pressboard.

\begin{tabular}{cccc}
\hline $\begin{array}{l}\text { Number } \\
\text { of pressboards }\end{array}$ & $\begin{array}{c}\text { Mode } \\
1^{\text {st }} \text { axial } \\
/ \mathrm{Hz}\end{array}$ & $\begin{array}{c}2^{\text {nd }} \text { axial } \\
/ \mathrm{Hz}\end{array}$ & $\begin{array}{c}3^{\text {rd }} \text { axial } \\
/ \mathrm{Hz}\end{array}$ \\
\hline 10 & 332.2 & 810.6 & 1385.3 \\
12 & 362.8 & 884.2 & 1510.5 \\
14 & 390.6 & 951.2 & 1624.1 \\
16 & 416.3 & 1012.6 & 1728.2 \\
18 & 440.2 & 1069.7 & 1824.7 \\
20 & 462.6 & 1122.9 & 1914.6 \\
\hline
\end{tabular}




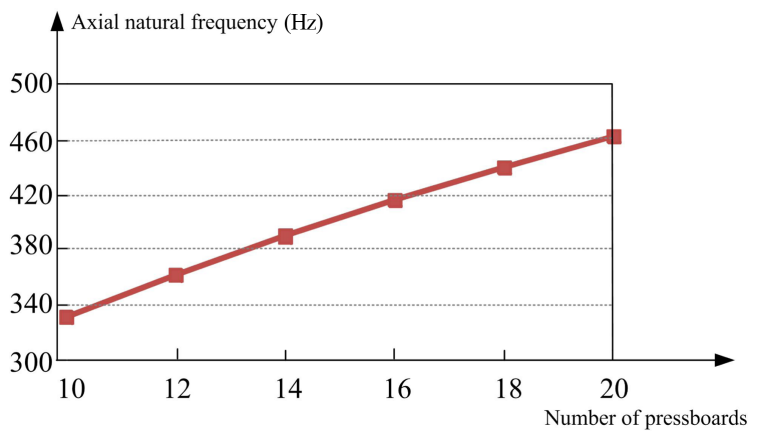

Fig. 5. (Color online) Curve of pressboard's number and frequency.

Table 6 lists the natural vibration frequency according to the number of pressboard, and Fig. 5 shows the corresponding curve of pressboard's number and frequency. It can be seen that increase of the pressboard's number and increase of the pressboard's width has the same effect on the natural vibration frequency.

Insulation of the transformer winding are mainly the pressboard and turn insulation, whose materials are insulation board [13, 14]. For the insulation board, the static stiffness is nonlinear, whose stress-strain relationship in a certain range $\left(d: 0 \sim 10^{3} \mathrm{MPa}\right)$ can be expressed as:

$$
\delta=a \varepsilon+b \varepsilon^{3}
$$

where, $a$ is the linear coefficient, $b$ is the hardening coefficient, which can be obtained by loading and deformation test $[15,16] . a=1.05 \times 10^{2} \mathrm{MPa}, b=1.75 \times 10^{3} \mathrm{MPa}$.

So the Young modulus is:

$$
E=\frac{\mathrm{d} \delta}{\mathrm{d} \varepsilon}=a+3 b \varepsilon^{2}
$$

Assuming that the pre-compression is $T$, it can be obtained that

$$
\frac{T}{A}=a \varepsilon+b \varepsilon^{3}
$$

Accordingly, pre-compression can be simulated by changing the equivalent young modulus of the pressboards.

The corresponding equivalent stiffness is:

$$
K=\frac{E A}{h}
$$

where, $h$ is the height of pressboards.

From the equation (16) and the equation (17), it can be seen that increasing the pre-compression can improve axial natural frequency as $f \propto \sqrt{ } K$.

Table 7 shows the natural vibration frequency according to the pre-compression, and Fig. 6 is the corresponding curve of pre-compression and frequency.
Table 7. Natural vibration frequency according to pre-compression.

\begin{tabular}{ccccc}
\hline \hline \multirow{2}{*}{$\begin{array}{c}\text { Pre-compression } \begin{array}{c}\text { Young modulus of } \\
\text { thPa }\end{array} \\
\text { the pressboards } \\
\text { /MPa }\end{array}$} & \multicolumn{3}{c}{$\begin{array}{c}\text { Natural vibration } \\
\text { frequency/Hz }\end{array}$} \\
\cline { 3 - 5 } & 128.64 & $1^{\text {st }}$ axial & $2^{\text {nd }}$ axial & $3^{\text {rd }}$ axial \\
\hline 1.0 & 137.43 & 248.63 & 497.55 & 746.71 \\
1.5 & 145.56 & 258.71 & 508.92 & 764.93 \\
2.0 & 153.18 & 262.83 & 527.75 & 795.63 \\
2.5 & 160.37 & 266.52 & 535.77 & 808.94 \\
3.0 & 167.15 & 269.82 & 543.05 & 821.13 \\
3.5 & & & & \\
\hline
\end{tabular}

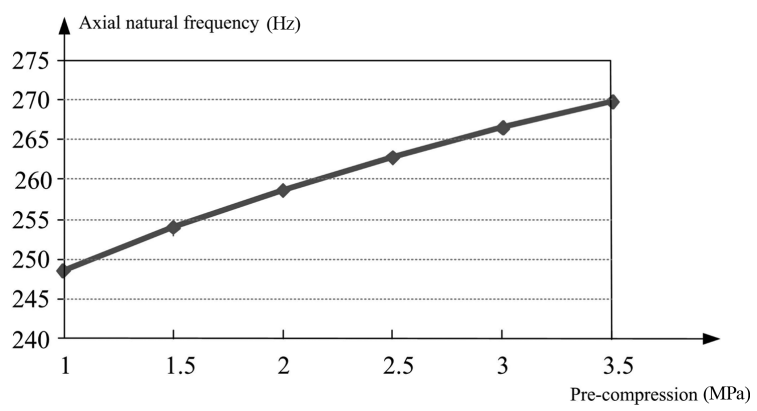

Fig. 6. Curve of pre-compression and frequency.

It can be seen that with the increase of pre-compression, each order axial natural vibration frequency is improving. This is because natural vibration frequency of the winding mainly depends on the degree of compaction after assembling. Accordingly, pre-compression can be simulated by changing the equivalent young modulus of the pressboards.

Tables 5-7 and Figs. 4-6 show the effect of pressboard's number, size and pre-compression on the natural vibration frequency of transformer winding. These factors should be taken into consideration in the design of transformer winding, which can be an effective way to avoid the resonance of winding.

\section{Conclusion}

Based on the elastic dynamics theory, and according to the elastic support equivalent principle of radial pressboards, a $2 \mathrm{D}$ model to calculate axial vibration natural frequency of power transformer winding is presented. It is verified that results of the 2D model are consistent with those of 3D model, obviously the former can achieve much higher calculation efficiency. Research shows the effect of pressboard's number, size and pre-compression on the natural vibration frequency of transformer winding, which should be considered in the design of transformer winding to avoid the resonance of winding. Finally, the proposed 2D 
model's effectiveness is verified when compared with tested ones.

\section{Acknowledgment}

Project supported by National Natural Science Foundation of China (51307082).

\section{References}

[1] Wang Luliang, Liu Wenli, and Yu Huifeng, Transformer, Shenyang (2013) pp. 14-17.

[2] Inge Johansen and Harald Riege, Transactions of the American Institute of Electrical Engineers, America (1962) pp. 782-788.

[3] Li Wenhai, Transformer, Shenyang (1997) pp. 18-22.

[4] S. K. Sahoo and S. Gopalakrishna, 2014 IEEE Students' Technology Symposium, West Bengal (2014) pp. 341346.

[5] Liu Xiaoli, Harbin University of Science and Technology, Heilongjiang (2008) pp. 1-59.

[6] Yu Xiaohui, Li Yan, Jing Yongteng, Li Hongkui, Transformer, Shenyang (2010) pp. 6-8.

[7] Shao Yuying, Rao Zhushi, Xie Poan, Jing Bo, Jing Zhijian,
Noise and Vibration Control, Shanghai (2006) pp. 51-53.

[8] Li Yan, Zhou Wei, Jing Yongteng, Sun Xin, 2011 International Conference on Electrical Machines and Systems (ICEMS), Beijing (2011) pp. 1-4.

[9] Ji Shengchang, Wang Junde, Li Yanming, Advanced Technology of Electrical Engineering and Energy, Beijing (2006) pp. 35-38.

[10] Ji Shengchang, Wang Junde, and Li Yanming, Advanced Technology of Electrical Engineering and Energy, Beijing (2006) pp. 48.

[11] Hadiya Pritesh, M.S. Thesis, Blekinge Institute of Technology, Sweden (2012).

[12] Zhang Bo, Li Yan, and Fang Xiaowen, 2014 International Conference on Information Science, Electronics and Electrical Engineering (ISEEE), Sapporo (2014) pp. 341345.

[13] Li Hongkui and Li Yan, Electric Machines and Control, Harbin (2010) pp. 98-101.

[14] Li Hongkui and Li Yan, Electric Machines and Control, Harbin (2010) pp. 106.

[15] M. R. Patel, IEEE Transactions on Power Apparatus and Systems, America (1973) pp. 1558-1566.

[16] M. R. Patel, IEEE Transactions on Power Apparatus and Systems, America (1973) pp. 1567-1576. 